\title{
Scaffolding norms of argumentation-based inquiry in a primary mathematics classroom
}

\author{
Katie Makar $^{1} \cdot$ Arthur Bakker $^{2} \cdot$ Dani Ben-Zvi ${ }^{3}$
}

Accepted: 2 September 2015 / Published online: 16 September 2015

(C) The Author(s) 2015. This article is published with open access at Springerlink.com

\begin{abstract}
Developing argumentation-based inquiry practices requires teachers and students to be explicit about classroom norms that support these practices. In this study, we asked: How can a teacher scaffold the development of argumentation-based inquiry norms and practices in a mathematics classroom? A primary classroom (aged 9-10) was videotaped during the school year to address this question. Using key features of scaffolding (diagnosis, responsiveness, handover to independence) we analysed strategies the teacher used to establish the required norms and practices. Interviewed reflections from the teacher provided further insights into her intentions and adaptive responses to students' emerging practices. The analysis showed how the teacher constantly diagnosed the classroom norms and responsively used strategies that changed as norms emerged, developed and stabilised. After nine months, there was evidence of argumentation-based inquiry norms practiced by students, independent of the teacher's presence.
\end{abstract}

Keywords Argumentation-based inquiry (ABI) . Classroom culture $\cdot$ Classroom talk $\cdot$ Inquiry norms . Inquiry practices $\cdot$ Mathematical inquiry $\cdot$ Scaffolding

\section{Introduction and background}

In contrast to traditional mathematics classrooms that focus on reproduction of procedures, inquiry-based classrooms

Arthur Bakker

a.bakker4@uu.nl

1 The University of Queensland, Brisbane, Australia

2 Utrecht University, Utrecht, The Netherlands

3 University of Haifa, Haifa, Israel value building a climate of intellectual challenge (Goos, 2004). "Rather than rely on the teacher as an unquestioned authority, students in [inquiry-based] classrooms are expected to propose and defend mathematical ideas and conjectures and to respond thoughtfully to the mathematical arguments of their peers" (p. 259). In our study, mathematical inquiry is taken to be the process of collaboratively addressing complex, ambiguous tasks (ill-structured, following Reitman, 1965) using mathematical evidence. The addition of "argumentation" emphasises negotiation and the discursive aspects of inquiry. For example, young students may address a question such as "What makes the best map?" (Fry, 2013), where they would collaboratively generate valued qualities in a map (to negotiate what they meant by the ambiguity of "best"), design a map with these qualities, and seek to convince peers that it fits their criteria for the "best" map.

Siegel and Borasi (1994) argue that inquiry classrooms in mathematics embrace the complexity of knowledge creation, managing doubt, ambiguity, anomalies and contradiction as a part of that process. Students are expected to recognise that their solution is contingent on the decisions they make, and the context and values that frame the problem. They see knowledge as collaboratively developed with social interactions supporting the process of knowledge creation and diversity as valued. Teachers take up a critical role of supporting student inquiry, "establishing a radically different set of social norms and values in the classroom as well as finding ways to invite students into the inquiry process, and support them as they engage in the process" (p. 210). Finally, in inquiry classrooms students are expected to share the responsibility of learning, take risks, listen to and negotiate with peers and reflect on learning. This requires intellectual risk, trust and socialisation of practices that enable them to contribute to knowledge creation. Like 
much of the research on mathematical inquiry, Siegel and Borasi's list is aspirational, but offers little detail on how these practices develop or are supported.

Uptake of inquiry has been slow in mathematics as a number of challenges exist for both teachers and students. The challenge addressed in this article is that of developing suitable classroom norms and practices required to promote argumentation-based inquiry. The goal of this article is to understand, by means of analysing a promising case, how a teacher established norms for argumentation-based inquiry in her classroom. In addressing this goal, we focus on the following research question: How can a teacher scaffold students' development of argumentation-based inquiry norms and practices in a mathematics classroom?

\subsection{Developing norms and practices of argumentation-based inquiry}

In this article, we focus on classroom norms and practices of argumentation-based inquiry in both small group and whole class settings. By norms, we refer to classroom level cognitive and social structures operationalised through the collective expectations of the teacher and students about what count as appropriate activities and interactions (Cobb, 2002; Enyedy \& Stevens, 2015; Webb et al., 2014). Practices encompass the broader space of classroom activities and interactions; as they are negotiated into shared norms, they often become tacit unless violated (Cobb, 2002). Accepted norms and practices in mathematical inquiry include "explaining and justifying solutions, attempting to make sense of explanations given by others, indicating agreement or disagreement, and questioning [conflicting] alternatives" (Cobb, 1999, p. 7). Cobb (2002) argued that three key types of norms constitute classroom mathematical practice: normative purpose (shared goals of an activity), normative standards of argumentation (what counts as a legitimate argument in terms of claims and support that would be expected by the teacher and students), and normative ways of reasoning with tools and representations. Translating these into an argumentation-based inquiry classroom, normative practices would focus on having a shared goal of authentically responding to the inquiry question, generating a legitimate and justifiable solution, being explicit about the evidence and process of solution, anticipating critique, and privileging expectations to think and reason mathematically.

The use of mathematical evidence takes on particular meanings in each stage of an inquiry (Wells, 2014). In the initial stages, students imagine a possible outcome and attempt to consider what evidence may be needed to respond to the inquiry question. This process of "envisioning evidence" (speculating evidence needed to solve the problem) assists students to ensure that they plan for and focus on the mathematics in solving the problem (FieldingWells, 2010). Inquiry problems are complex, so the entire pathway from beginning to end is not necessarily visible (Zack \& Reid, 2003). As movement is made (or not) towards a viable solution, evidence provides a focal point for judging ideas, progress, and next steps within the problem context (Brown, Collins, \& Duguid, 1989). In argumentation-based inquiry, the reasoning linking questionevidence-conclusion is made explicit—as students share not only their final solution, but also their progress along the way. When students defend their final solution, mathematical evidence plays a critical role in convincing their peers of the validity of their solution and incorporates the solution pathway (method) as a natural part of their defence.

In her research with collaborative groups, Webb and her colleagues (2014) reported that while explaining ideas in mathematics was useful, there were far greater achievement gains when students engaged with each other's ideas (e.g., challenging peers, clarifying conflicting ideas, proposing alternatives and building on others' ideas). This level of engagement goes beyond the typical requests for students to justify their answers. However, Yackel and Cobb (1996) observed in the development of norms, that students struggled with having a "taken-as-shared sense of when it is appropriate to contribute" and "the actual process by which students contribute" (p. 461, emphasis in the original). Goos (2004) argued that these norms of participation in mathematical inquiry are based on the assumption that mathematical thinking is an act of sense-making and includes argumentation. Under this assumption, the teacher would model sense-making for students and encourage them to take ownership for developing mathematical solutions, recognising the intellectual risk involved in asking students to go beyond passive listening and share incomplete ideas with others.

Risk is woven into all aspects of the inquiry process, from the initial formulation of the problem through to the final presentation and evaluation of end results. Given their prior school experiences, many students may be hesitant to immediately trust that teachers are really interested in hearing their ideas and not just waiting to catch them making a mistake. Hence, the first days, weeks and months of the class take on special significance as students become socialized into practices that depend on their contributions and learn that a range of responses, not just one, is valued.

(Siegel \& Borasi, 1994, p. 211)

To encourage student risk-taking, Goos suggested that the teacher would withhold judgement on students' suggestions and elicit comment and critique from peers. Slowly, students would then begin to offer conjectures and critique 
without teacher prompting. The teacher and student practices were clearly inter-linked. If the teacher consistently judged student contributions as correct or incorrect, students would probably be less likely to contribute their partial and emerging thinking.

Risk-taking through sharing incomplete ideas is one of the key practices of argumentation-based inquiry that we are concerned with. Other practices, derived from the literature on classroom talk and collaboration (e.g., Cobb, 1999; McCrone, 2005; Mercer, 2008; Webb, 2008; Webb et al., 2014), are the need for active listening, explaining and justifying to peers, and building on others' ideas. The literature also points to the continuous work required by the teacher to establish such norms (e.g., McClain \& Cobb, 2001; Yackel \& Cobb, 1996). These norms support and enable the emergence and regulation of argumentation-based inquiry practices. In line with the idea of social scaffolding to support norms and student participation in discourse (Williams \& Baxter, 1996), we explore in this article how the aforementioned norms can be scaffolded.

\subsection{Scaffolding}

Scaffolding was originally described as a temporary, adaptive support provided by a teacher or more knowledgeable other to assist a student to solve a problem that they would not normally be able to solve on their own (Smit \& Van Eerde, 2013; van de Pol, Volman, \& Beishuizen, 2011). Over the past decades the metaphor has been extended to include whole-class settings (Smit, Van Eerde, \& Bakker, 2013), learning artefacts as scaffolds (Sherin, Reiser, \& Edelson, 2004), and long-term supporting systems such as curriculum (Cazden, 2001). For longer-term processes such as the learning of mathematical language or the establishing of norms, we need a conceptualisation of scaffolding that accounts for this time dimension (cf. Mercer, 2008). Smit et al. (2013) offered such a conceptualisation that stressed the distributed, layered and cumulative nature of scaffolding, which we anticipate in the establishment of norms. The term "distributed" here referred to the distribution across different lessons, agents and scaffolds (cf. Tabak, 2004); "layered" to the fact that scaffolding characteristics such as diagnosis and responsiveness not only happen in teacher-student interactions in the classroom but also between lessons (e.g., responses to diagnoses in lesson planning); "cumulative" referred to the phenomenon that it typically takes many diagnoses and responsive actions by the teacher, in this case to establish a norm.

Researchers have argued against applications of the scaffolding metaphor that are overly general as if it were "a technique that can be applied in every situation in the same way" (van de Pol, Volman, \& Beishuizen, 2010, p.
272), but must remain dynamic in order to adapt to the specific situation, task type, and student response. Renshaw (2013) cautioned social and emotional scaffolding must be included to avoid rigid application of strategies that do not respect diverse learners. To delineate our use of scaffolding in this article, we focus on three key features of scaffolding - diagnosis, responsiveness, handover to independence-used by Smit and her colleagues (2013) and include both cognitive and social scaffolding.

Promising effect studies in mathematics education often involved the use of short, textbook type problem solving tasks, for example with solution plans or worked examples as scaffolds (Schukajlow, Kolter, \& Blum, 2015). In some cases social scaffolding was taken into account (e.g., Speer \& Wagner, 2009), but research on scaffolding norms is rare. Scaffolding long-term processes requires substantial commitment from the teacher; yet studies have reported that teachers typically find it hard to adapt to student needs (Webb, 2008) and in most cases, either do not diagnose a student's understandings before providing support or their support does not respond to the student's particular difficulties (van de Pol et al., 2011). Webb and her colleagues (2014) point to the critical importance of a teacher's follow-up questions (e.g., pressing for details to make thinking more explicit) for supporting students to engage with each other's ideas. However, more is needed than just knowing these questions are important. Franke and her colleagues (2015) argued that

There is a need to study how teachers are making the in-the-moment decisions to probe, scaffold, and position students; to extend an interaction around a student idea rather than to move on to another idea; to invite other students to contribute rather than only providing a teacher-generated explanation. (p. 21)

Research on scaffolding has typically focused on oneto-one or small group interactions, "because whole-class scaffolding is complicated by the multitude of ZPDs in the classroom" (van de Pol et al., 2011, p. 48). However, student interactions beyond the small group are also critical to develop. In a study that focused on whole-class scaffolding (Herrenkohl, Palincsar, Dewater, \& Kawasaki, 1999), students were supported to assume appropriate audience roles in questioning, commenting, critiquing-including both what and how they could respond to their peers. Their focus on student-student interaction in whole class discussions extended classical studies in scaffolding teacherstudent interactions in one-to-one or small group settings. Herrenkohl et al. emphasised the critical nature of classroom culture that are missing in many studies of wholeclass scaffolding, arguing for a need to make "sociocognitive roles explicit to students so that they can engage in significant cognitive work together. ... [And] to support the 
development of learning communities that emphasize the role of discussion" (p. 489).

Scaffolding classroom talk in small group and whole class discussion is a key concern for classroom-based inquiry because of its emphasis on sense-making (Brown et al., 1989; Goos, 2004), collaboration (Quintana et al., 2004), and the need for making thinking visible (Wells, 2014; Linn, 2000). Elaborating on the research of Brown and his colleagues (1989), a scaffolding end-goal of handover to independence in an inquiry-based environment would focus on students' confidence to use peers as social and cognitive resources. In both small group and whole class settings where students generate, share and report ideas, independence would also observe students drawing on "the important structuring and supporting cues that arise from the context" (p. 34), using their collaborative environment for "confronting ineffective strategies" (p. 40), and evaluating "the adequacy of the solution they reach" (p. 36). Rather than rely on the teacher to check or present the "correct" method, their own "inventive heuristics" (p. 36) would be "assessed with respect to a particular task" (p. 38) and the utility of ideas "judged in the context of the problem to be solved and the interests of the problem solvers" (ibid).

In order to gain insight into the required scaffolding process, we devised the following research questions:

How can a teacher scaffold students' development of argumentation-based inquiry norms and practices in a mathematics classroom?

- What did student practices and norms look like at different stages over a year?

- How did a teacher diagnose, respond and develop students' independence in response to the progress of students' emerging argumentation-based norms?

\section{Methodology}

\subsection{Context and participants}

The data presented in this study come from a larger project on argumentation in mathematics and statistics involving three teachers over three years in a middle class suburb of a capital city in Australia. The overall aim of that study was to theorise and improve on the uses of argumentation in classrooms practicing mathematical and statistical inquiry. Design research (Cobb, Confrey, diSessa, Lehrer, \& Schauble, 2003) was adopted in the larger study in order to use increasingly focused cycles to: generate theoretical understandings of argumentation in mathematics and statistics, respond to changing conditions in the classroom, and capitalise on the teacher's expertise to engineer the learning environment. This article draws on data from a classroom in the last year of the study; the case study focuses on how the teacher scaffolded norms of argumentation-based inquiry over a year in her mathematics classroom.

Data from Kaye Bluett (pseudonym) and her students during the school year (four 10-week terms) are presented. Mrs Bluett was an experienced teacher who had been teaching mathematical inquiry for more than 6 years in research projects conducted by the first author. Mrs Bluett's data were selected because she was particularly interested in scaffolding argumentation-based inquiry norms. The 26 students in her Grade 4 class (9-10 years old) represented a range of performance levels, with several students receiving additional learning support. Students had neither prior experience with argumentation-based inquiry nor collaborative learning. Student groupings were typically assigned for each unit in an unbiased way (e.g., numbering off $1-8$ to make 8 groups of 3-4 students) to provide students opportunities over time to work with a diversity of peers. The first author videotaped the lessons, discussed the lessons with Kaye Bluett and occasionally asked the children questions during the lessons. The experience of the teacher, synergies between the teacher and researcher, and presence of the researcher in the classroom was therefore more ideal than would be typical in a classroom.

\subsection{Data collection}

The focus of data collection was on the collective development of norms and practices of argumentation-based inquiry rather than tracking individual students' progress (Towers, Martin \& Heater, 2013). These data consisted primarily of the 17 videotaped lessons (60-90 min in length) in which Kaye Bluett was teaching mathematical inquiry (or introducing collaborative problem solving in Term 1), and three semi-structured interviews with the teacher over nine months. In the interviews, Mrs Bluett was asked about her intentions for developing her students' argumentation norms (March), to reflect on their progress, and to discuss her plans for the following term (June). In a final interview, she reflected on her scaffolding over the year (December).

Video data were collected March-November 2014 as the class learned mathematics through problem solving and inquiry in four units designed by the teacher.

1. Term 1: Problem solving. Students were introduced to the concept of evidence, developed skills in articulating and documenting their reasoning and practiced working effectively with peers. They worked to address problem-solving tasks, shared in pairs, then discussed their solutions in class. Three lessons were videotaped (March 2014). 
2. Term 2: What is the best route to school for a walking school bus? In this inquiry unit, students collected data on how far they lived from school to plan a community walking route to school (www.walkingschoolbus.org). Three lessons were videotaped (June 2014).

3. Term 3: How far does a paper airplane fly? Students built a paper airplane from instructions and worked in groups to determine how far their planes typically flew. Six lessons were videotaped (August-September 2014; data not presented in this article).

4. Term 4: What is the typical time it takes for a Year 4 student to read a book? Students worked in groups to devise a method to answer the inquiry question. They collected data on times needed to read sections of chapter books to estimate the time to read an entire chapter book. Five lessons were videotaped (November 2014).

In a professional development session in March, the teachers read a paper (McCrone, 2005) in which students progressively improved their classroom talk during the year. Issues around developing classroom talk that the teachers had experienced in their classroom were discussed. At the end of the day, the researcher laid out 45 cards containing issues, concepts and strategies discussed during the day (e.g., from McCrone and a short presentation by the researcher about argumentation) and concepts, challenges or strategies that had emerged in discussion during the project (e.g., "agency", "verbalising mathematical ideas", "assessment", "students' roles", "evidence", "teacher questions"). From this display of cards, the teachers selected the following four practices as ones that they valued collectively and wanted to focus on developing in their students over the year. These choices were not directed by the researcher, but were likely influenced by the discussions during the session:

\section{- Active listening}

- Justifying and explaining to peers

- Intellectual risk-taking: Sharing incomplete ideas

- Building on others'ideas

These were put together into a poster for their classrooms; progress on these was specifically addressed in the interviews. Individually, teachers also developed additional practices that they valued. Those relevant to this article are discussed in the results section as they arose.

\subsection{Data analysis}

The interview and video data went through an approach to video analysis involving four phases modified from Powell, Franscisco and Maher (2003). These phases were non-linear, although described here sequentially. As new insights were gained, data were often reviewed again to seek potential evidence or counter-evidence for these insights.

In the first phase of analysis, logs of each audio and video file catalogued their content. Timestamps and screen shots of videos assisted with visualisation of whole class and small group structures. Specific sections were flagged as potentially rich excerpts for further analysis. Emphasis was placed on identifying excerpts in which: the teacher was explicitly scaffolding classroom argumentation norms and practices; students were attempting to apply these practices; or students missed a rich opportunity to apply these practices (negative cases). Indications of teacher scaffolding included: doing something she had expressed as an intention in an interview or from one of the four practices identified in the initial professional development (Sect. 2.2); explaining, reinforcing, questioning about, or reminding students of norms on posters; and using student behaviours (positive or negative) to illustrate desired actions. Episodes were also flagged which illustrated evidence (or non-evidence) of student independence.

In the second phase, flagged episodes were transcribed and annotated to note how the particular episode illustrated an example or outcome of scaffolding.

In the third phase, each episode was reviewed again in reverse order (last video first) to seek traces of how later examples of classroom discussion practices were developed. This was particularly important to follow up on the results of teacher's intentions, diagnoses and specific actions to promote the argumentation-based inquiry norms that developed. Insights were tagged with phrases to assist with identifying emerging threads through the data. The audio files and videos were reviewed again in their entirety to seek further examples that may not have been obvious previously. Newly identified episodes were processed as in phases 1-3. Note that there was not a consistent unit of analysis in which interactions could be reduced to the level of individuals or turns, and subsequently counted; rather analyses focused on the explanatory power of relationships and interactions within the discourse (cf. Enyedy \& Stevens, 2015).

Finally, further literature was sought to deepen understanding of emerging conjectures, and episodes were selected which would illustrate key moments in the development of argumentation-based inquiry norms and practices in that classroom. A small number of episodes were selected as those which succinctly illustrated norms being practiced or developed. Because not all excerpts could be presented, preference was given to those in which: there was a link between the teacher's interviews and enactment in the classroom, a mix of small group and whole class interactions could be shown and norms being discussed 
were exemplified. Discussions among members of the research team took place throughout the analysis in order to negotiate potential narratives (Powell et al., 2003). Where questions arose, transcripts were shown to the teacher and she assisted in clarifying actions.

\section{Results}

We start with a classroom episode in which students were functioning well in their developing argumentation-based inquiry practices, independently from the teacher. Then the development of these practices is tracked from the start of the year to observe how the teacher slowly scaffolded this development through diagnoses and responsive use of particular teaching strategies. By starting from the end of the year first, it provides strong contrasts between the teachers' actions in developing classroom norms and students' participation in these norms (comparing the end and beginning side-by-side).

\subsection{Term 4: established norms}

One of the key goals of scaffolding is to hand over responsibility to learners. In argumentation-based inquiry, this outcome does not aim to have students perform a task independently but to develop independence in argumentationbased inquiry norms. We begin with an episode near the end of the school year when students were finalising their solutions to the inquiry question, What is the typical time it takes for a Year 4 student to read a book? In this lesson, groups had prepared draft posters of their inquiry solution and were seeking feedback from peers. In the episode below, Wes and Shane offer feedback to Jake, Jonah and Emma. The teacher rotated between groups but had not yet arrived at this group, so one may consider these students as working independently.

Wes: $\quad$ For your table I was maybe wondering like, you could write, like be a bit more specific, like time to read a chapter and then like ... [calculating] total time reading the book in minutes or something. Because I don't really know what you're talking about.

Jake: $\quad I$ don't even get it (what we wrote)! Total time? What's the total time? (Mocking themselves for not showing this information on their poster.)

Wes: $\quad .$. On your diagram here I really like how you made your answers [data] into colours and put it on [a graph]. It really is easier [to read] now. ... Um, what's like, the pattern in your data?

Jake: Um. (Pause as he thinks)

Wes: (Helping out with examples) Like range, spread.
Jonah: There. (Points at graph)

Shane: Put some borders in between the - (he can't think of the word "clump", but puts his fingers on the graph to show where to draw lines around the clump.)

Wes And you've got it really nicely set out.

Shane: Yeah it's really nice, but put ... barriers where most of the data is ... because I can't see where it's bunched. (24:17, Classroom video 24 November 2014)

Wes and Shane provided their peers with feedback to improve the presentation of their solution. Wes' language was tentative and respectful in telling the group that there was not enough detail to "know what you're talking about." Jake's jovial response suggested he did not find Wes' feedback as a personal criticism, implying that it was a normal practice. The positive and critical feedback given by Wes and Shane was non-trivial and genuinely provided the second group with ways to improve the presentation of their final results. The students used terms they had learned in class to describe distributions (range, spread, clump) and ways to show an interval to estimate the answer (barriers around "where it's bunched").

We argue that this episode provides evidence that the group was demonstrating the inquiry norms Mrs Bluett was aiming for them to enact such as active listening (Jake), justifying and explaining to peers (Wes), building on the ideas of others (Shane), and questioning and challenging ideas (Shane). There was no teacher present during this exchange, suggesting that these students were practicing these skills independently (a wireless mic was next to them with the researcher filming from several feet away; the students were used to her presence). We are not claiming that all students demonstrated this level of exchange, and acknowledge Emma's voice being absent. However, nearly all groups were observed by the teacher and researcher to be independently enacting expected norms, with the teacher rotating between groups to listen to and further promote students' exchanges. These norms constituted the end-goal of the teacher's scaffolding efforts over the year as evidenced by her final interview (see Sect. 3.4).

\subsection{Term 1: How the scaffolding process started}

The children did not arrive at the start of the year with fluency of these norms. In order to answer our research question of how Kaye Bluett, the teacher, scaffolded children's argumentation practices at the start, we return to the first term (March). Given our focus on long-term scaffolding, we highlight her diagnoses of what happened in her classroom, how she responded to children, her intentions to change things and her strategies to foster argumentation-based 
Fig. 1 Two classroom posters on expectations about classroom talk (left) and collaboration (right) to scaffold norms of argumentation-based inquiry

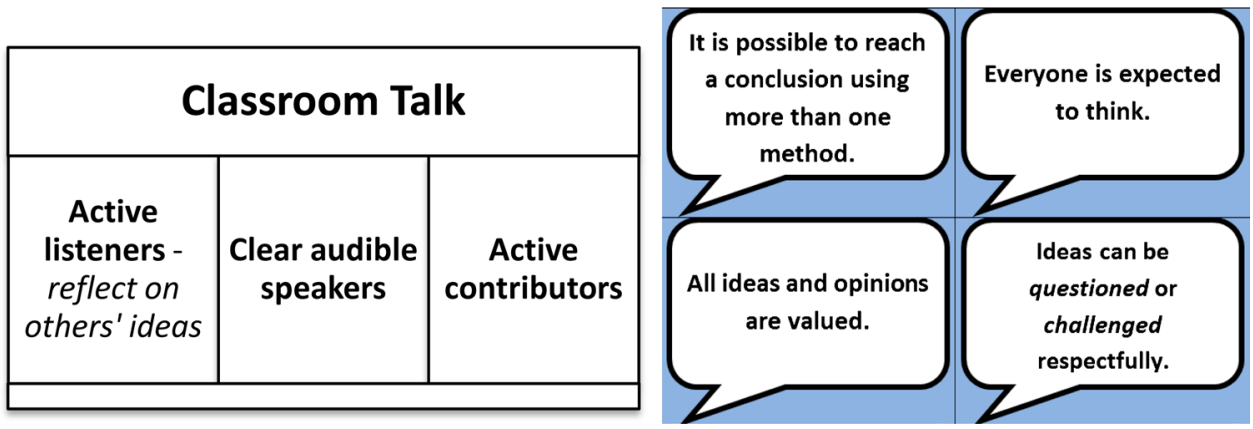

inquiry norms and handover of responsibility to the children. The problem the children worked on in Term 1 was a problem solving scenario, as Mrs Bluett felt that developing initial norms of working, speaking and listening collaboratively would be more effective with a series of problems that were shorter in duration and less open-ended.

Before the first lesson, Kaye Bluett explained her intentions and some strategies for beginning to develop the classroom norms and practices. A key aspect of this was developing support structures: frameworks of skills and values that would be used throughout the year.

I guess it is with classroom culture-it's got to be a model. It's got to be having ways, being creative in ways to ensure everyone is working collaboratively, that everyone is having their say, that everybody's opinions are feeling valued. Those sorts of things ... are a way of developing classroom culture. Having those strategies when things are not working .... [means] you can come and specifically target those elements. (10:35, Interview 7 March 2014)

One strategy that Mrs Bluett used to develop classroom norms therefore was to create models (or frameworks) around practices she was expecting. She created posters with phrases that she referred to during the year (e.g., Fig. 1), one of which laid out her expectations for quality "classroom talk" with roles for the listener, speaker and all group members. Another focused on expectations when working collaboratively.

From these models, Mrs Bluett supported students' adoption of these practices using the language on the posters to regularly acknowledge positive behaviours. This act was intended to reinforce these behaviours as valued in the class so that students would adopt them independently.

I guess even reinforcing and rewarding-it's not the word I want-acknowledging is it? Valuing? Reinforcing, acknowledging, valuing ... when you actually see evidence of it - if you want classroom culture like this, you reward it. (11:53, Interview 7 March 2014)
Her talk about acknowledging and valuing indicates her strategies to encourage students, while her speaking of evidence illustrates how she diagnosed how well students contributed to classroom talk during classroom interactions. An episode from class a few days later acted as an example of how Kaye Bluett reinforced and showed her valuing of positive student norms. First, she explained to students what she meant by being an "Active listener" (Fig. 1, left). To validate and reinforce the norms she was trying to develop, the teacher illustrated them using the students' current behaviours. In doing so, she was diagnosing and responding to students, reinforcing and valuing positive illustrations (explained in her interview).

Mrs Bluett: $\quad$ Now today I had two or three groups on the floor working brilliantly at classroom talk. So congratulations to those six people. In fact something Bill did, (then to Bill) you might want to share with everybody, what did you and your partner do for classroom talk.

Bill: $\quad$ Sat beside each other, and um, gives you more of an idea of the story.

Mrs Bluett: $\quad$ Yes, so they were sharing. And so instead of Bill sitting facing his partner, he and his partner actually sat side-by-side. ... So when Jonah was reading, Bill could hear what he was saying but he could also see what he was saying. So he was actively listening, he was giving himself every opportunity to question what Jonah was saying and an active contributor. (1:46, Classroom video, 12 March)

Using students as examples to reinforce what she valued was a regular occurrence in Mrs Bluett's class. The teacher frequently used phrases such as "I like the way that students are..." as a way to scaffold the norms she was expecting. To further empower students towards ownership of these behaviours (shifting them towards independence), she had the students themselves explain what they did, as in 
the example above with Bill. Once Bill told the class what he and Jonah were doing, Mrs Bluett re-expressed Bill's words to develop and improve students' language of the norms she was trying to develop. Thus re-stating is another strategy for scaffolding by diagnosing and responding to students' expressions of their behaviours. Her exemplification of Bill and Jonah went beyond their visible actions to highlight the implications of these actions; for it was not the specific actions she wanted students to copy, but the intentions of these actions.

Following this exchange, students were given a word problem to solve and then presented their individual solution to their assigned partner, including evidence and multiple representations. They were also expected to practice active listening. A few students adopted the practices the teacher was encouraging, although it was unusual to find two such students in the same pair. In the example below, Bill and Chloe sat beside each other (instead of opposite), a practice validated by Mrs Bluett previously.

Bill: The grasshopper [won] because one-third is larger and greater than a quarter.

Chloe: ... (To Bill) Show me your evidence. (Bill hesitates so Chloe begins). OK, I wrote one-third is bigger than one quarter. I drew a picture and then (pointing to her drawing) there's one quarter is smaller because it's not as big. Then on the number line I drew, I also drew a [fraction] wall. ...

Bill: That's good, good. I need to copy a few ideas. (40:58)

This pair exhibited norms that the teacher was trying to develop in students. Bill justified his answer ("because one-third is larger"). Chloe could have simply agreed and stopped, satisfied that they had the correct answer, but she prompted him further for evidence. When he didn't respond, she provided her own evidence, and more than one way to represent the problem, as encouraged by one of the posters (Fig. 1, right). From her sharing of evidence and reasoning, it could be inferred that she acknowledged the evidence as part of the solution, or at least accepted evidence as what the teacher expected. Their response to each other suggested that solutions were neither private nor "owned" but expected to be shared and built upon. Chloe and Bill illustrated what Mrs Bluett expected her students to be doing. Most groups however, struggled to carry out the norms the teacher expected (active listening, explaining and justifying to peers), as illustrated below. Like most groups in the class, Shane and Ella sat facing one another.

Shane: Then I wrote the grasshopper jumps one-third each time so it only needs to jump 12 times. The beetle has to jump 15 times (sic) and then I drew the grasshopper how it's got, um, three quarters, I mean three-one-third. And then with the beetle I wrote that it had one quarter.

Ella: I really like-

Shane: (interrupting) — and I wrote that the grasshopper was gonna win.

Ella: I really like all your information about it.

Shane: $\quad$ Mmm and we're done! (35:32)

Shane explained his reasoning and answer, as would be expected, but his words and actions ("we're done!") suggested that he did not value hearing Ella's solution. Although Ella made some attempts, this group did not demonstrate the norms expected.

As the teacher rotated between groups to check on their progress and probe their thinking, she stopped the class occasionally to remind them that she expected everyone to be contributing (illustrating Tabak's, 2004, 'redundant scaffolding'). Norms require long-term development with ongoing support; therefore, students needed to be reminded regularly of expectations.

To further practice the norms, pairs presented their work using prompts (Fig. 2) to help them formulate questions to their peers. Mrs Bluett explained and modelled to students how she expected them to use these prompts in their role as an audience. They were pasted into their notebooks in Term 1 and decreasingly referred to often over the year. She then sent them into groups to practise their role as audience members.

In one group, Oliver presented his answer (with diagram) to six students who attempted to respond using the prompts. In their first attempt, students were challenged knowing how and when to contribute (Yackel \& Cobb, 1996). While they did not yet aim to make meaning of the speaker's intent, they did not just parrot the questions; rather they attempted to adapt them to the situation (Grace: "Did you consider scanning it?", using a process ('scan') they had used in problem solving lessons). These initial attempts, although stiff, were important:

1. They legitimised the practice of questioning peers, not typically a norm in mathematics classrooms.

2. They introduced an expectation to anticipate critique when sharing solutions and ideas.

3. The prompts assisted students in getting over the difficulty of breaching the silence following a presentation, lowering the risk needed to enter into the discussion.

4. Finally, it provided a starting point from which the teacher could diagnose and respond to their progress over time.

These represent Cobb's (2002) norms of a shared purpose to understand and improve the solutions of others, standards 


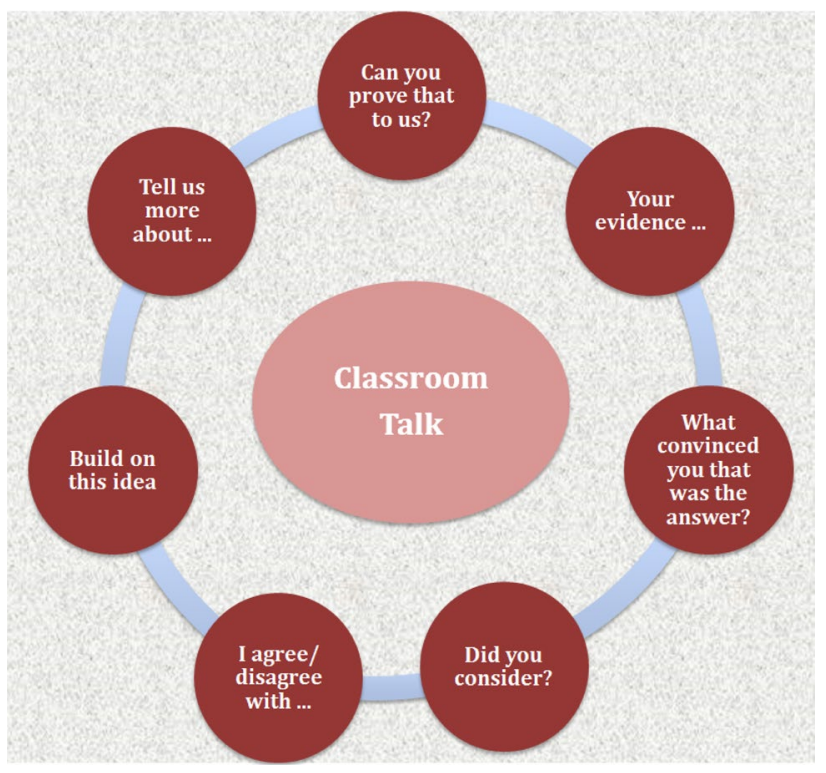

Fig. 2 Prompts given to students to scaffold their questioning of peers

of argument, expecting legitimate claims and evidence, and by including representations in explaining solutions.

The explicit nature of the teacher's talk and her actions in Term 1 were important as students: were introduced to what norms were expected using explicit frameworks, discussed how they were to engage in norms through teacher modelling and co-construction, and developed these norms through practice and valuing by the teacher. These explicit strategies, only some of which are mentioned here, did not end with the close of Term 1, however they sometimes became tacit as they moved from ideas into practices.

\subsection{Term 2: intermediate phase of scaffolding argumentation norms and practices}

A key focus of Term 2 was to give students repeated experiences practicing norms. Maintaining and developing these norms is a different pedagogical skill than starting out. Modelling and valuing desired practices were strategies that Kaye Bluett had been using across all subjects. In an interview discussing students' developing argumentation skills mid-year, Mrs Bluett assessed both students' growth and the areas that needed further development. This process of diagnosing students' progress also enabled her to then reflect on her planned response-pedagogical strategies to guide them towards independence.

Look, I think they have come a long way. They were pretty dreadful at the beginning of the year (laughs), so it can only get better. ... [I] have talked to them about, that there is more than one way that's possi- ble to do the task; [and] that everybody in the class is expected to think. So you can't just sit there and let it all wash over you; you have to give an answer. (0:49) ... For me, the one that I think needs further development is this intellectual risk-taking and the sharing of incomplete ideas. ... So I guess that's where I really want to keep pushing. ... "Okay, let's see what other people have done. If you are a bit stuck, you can use that." (3:09, Interview 27 June 2014)

Kaye Bluett recognised that even after the first term, students were struggling with a number of practices that were critical for more advanced skills such as building on others' ideas and taking intellectual risks by sharing incomplete ideas. By assessing students' progress to date and areas needing further improvement, Mrs Bluett demonstrated diagnosis, explaining that many students were still staying safe rather than taking risks by sharing incomplete ideas. Her support for students' improvement included a more focused effort ("pushing") by emphasising with students how sharing and building on incomplete ideas are productive practices for solving problems when you are stuck.

In Term 2, nearly halfway through the school year, the students were addressing a mathematical inquiry in which they needed to create the best path for a "walking school bus". Students used Google maps to generate directions from their house to the school, giving them a distance in hundreds of metres or in kilometres to the nearest tenth. The teacher took the class outside to create a physical representation of their collective data. They had not yet worked with dot plots and Mrs Bluett was hoping to encourage them to see a need to go beyond simply splitting the class into two groups of living close and far from school (their initial approach). She also hoped to improve their developing norms in argumentation-based inquiry.

Students were seated in two groups organised by Chloe: students who live less than $5 \mathrm{~km}$ and students who live more than $5 \mathrm{~km}$ from the school. In the set of exchanges below, the teacher illustrated for students what it means to build on others' ideas.

Mrs Bluett: What is the typical distance that students [in this class] live from school? If I look at the way that Chloe has organised our data can we answer that question now? (24:12, Classroom video 17 June 2014)

Mrs Bluett reminded students of the question and acknowledged Chloe's contribution as a starting point towards the solution. She again used the question to prompt students to challenge and/or build on Chloe's initial idea. These prompts scaffolded students' move toward independence by modelling a way for students 
to self-monitor whether their evidence was helping them to answer the question. Chloe herself recognised a problem.

Chloe:

Mrs Bluett:

Yes. (Pause) Not exactly.

If I ask people how far they live from school, what would I expect the answer to be from what we've just seen here? Jinny? (25:14)

In an inquiry classroom, ideas are intended to be public rather than personal. Rather than defend her solution, Chloe's rejection of it implied that she did not interpret a rejection of the idea as a negative and also made it easier for her peers to critique and build on her initial approach. This was further encouraged by Mrs Bluett's solicitation of others to respond as well.

Jinny:

Maybe we should put the groups into 0.1 or $1[\mathrm{~km}]$ sets. If we mix them all together it will be harder to organise.

Mrs Bluett: All right, at the moment can I say that students in [this class] typically live less than $5 \mathrm{~km}$ from the school?

Jinny: No

Mrs Bluett:

Could I say that? (Mostly students initially respond yes, but then some disagreement)

Chloe: $\quad$ Yes you could!

Mrs Bluett: $\quad$..Why could I say it? (25:31)

Jinny suggested that it may be better to organise them into smaller categories by tenths or whole kilometre distances. The teacher rephrased the question, prompting students to decide if the current arrangement in two groups would allow them to answer this question, or if Jinny's suggestion should be considered. Two groups provided some information, certainly more than the unorganised data. There was an expectation that students justify their answers, so rather than just acknowledge Jinny and Chloe's responses she pushed the class to explain their reasoning.

Chris: Because there's more people in this $[<5 \mathrm{~km}]$ group.

Mrs Bluett: $\quad$ Because there's a whole lot of people here. This is typical of our class (pointing to the bigger group of students). ... So I can say students [in our class] typically live less than five $\mathrm{kms}$ from the school. But Jinny is saying that I can make my answer better. Jinny wants us to make the answer better by doing what? (26:06)
The teacher had created an environment where students were encouraged to think and reason without worrying whether their answer was complete or even correct. This invitation to think aloud can encourage students to take intellectual risks to share their emerging, incomplete ideas. She summarised the discussion so far to demonstrate that she valued students' contributions to the developing argument. By acknowledging that Chloe's idea was an improvement over unorganised data, she affirmed that this did indeed answer the question; she further suggested that an answer to the question was not enough. However, she returned to Jinny's contribution to model what it meant to build on others' ideas.

Jinny: $\quad$ By putting the $0.1-1[\mathrm{~km}]$ people in a group.

Mrs Bluett: Why would we want to do that? Doesn't this show us now? If we do what Jinny says, what will that help us see?

Chloe: $\quad$ That maybe a whole lot of this chunk is only 0.1 and that a lot of other people are three to four, or just under 5 . ... What about the people who are just over, like 5.1? Like the two over there.

Mrs Bluett: I like what you're saying. This arrangement isn't really showing us how spread out it is. It is showing that anyone in here (pointing to the over $5 \mathrm{~km}$ group) can be between 5 and $12 \mathrm{kms}$. (26:43)

When Jinny repeated her suggestion, Mrs Bluett pushed her peers to explain why Jinny's statement improved on the current solution of putting students into two groups. By explaining Jinny's logic, Chloe demonstrated active listening. But active listening is not just listening, it is engaging with the reasoning of the speaker to make sense of their contribution. Chloe's response validated that Jinny's idea was building on her own. Mrs Bluett modelled a positive way to respond to ideas ("I like what you are saying"), co-constructed a solution process with the class and summarised how Chloe and Jinny's suggestions challenged the original solution to the problem.

Whole class discussions like this were not happenstance. Mrs Bluett explicitly worked to extend students' developing practices to become norms by (1) giving them opportunities to practice active listening, explaining and justifying to peers and expecting there to be more than one way to do a problem; and (2) modelling, co-constructing and reinforcing more advanced practices, such as sharing incomplete ideas, respectfully challenging suggestions and building on the ideas of others, all of which required greater intellectual risk-taking. Kaye Bluett's scaffolding required her to reflect on the progress they had made, then develop focused strategies to improve students' work. 
It was actively listening to what people were saying and it was justifying. ... There were nice glimpses but I didn't give them enough chances in the final stages to be able to show me more of this. (5:02) ... [Next semester] I want to get that more risk-taking and the more of sharing/completing ideas... and giving them the time to do that. ... [I plan] just pulling back a little bit, so that we can start letting them perhaps meet a few of the challenges and hit a few more walls. (12:25, Interview 27 June 2014)

In this interview, the scaffolding practices of diagnosis, response and handover are illustrated in the teacher's reflection. She recognised that students had made progress in active listening and justifying, but still needed further work in intellectual risk-taking. She saw the need to give them more opportunities to share and build on others' ideas. She planned to elicit more independence from students in the inquiry decisions by "pulling back a little bit" and allowing them to "hit a few more walls".

\subsection{Summary}

At the end of the year, Kaye Bluett reflected on the progress students had made in response to the scaffolding during the year.

The whole purpose of what we've been building on all year has been you know, taking kids right from that very first stage of having no real notion of what it means to talk with each other and through all the different inquiries we've been doing, to bring us to this. $(0: 14) \ldots$ That constant scaffold to try and, making sure that they're on the right page and to try and move forward. ... It doesn't matter what we're doing. ... I think it's just a culture that's developed. (12:41, Interview 3 Dec 2014)

In order to build towards the independence observed in the excerpt at the beginning of the article, there was a long road of explicit scaffolding undertaken by the teacher. Her commitment of a "constant scaffold" regardless of what they were doing (i.e., daily and across all subject areas) was critical for developing argumentation-based inquiry norms in her classroom.

\section{Discussion}

In this article we addressed the question: How can a teacher scaffold students' development of argumentationbased inquiry norms and practices in a mathematics classroom? More specifically, we wondered:
- What did student practices and norms look like at different stages over a year?

- How did a teacher diagnose, respond and develop students' independence in response to the progress of students' emerging argumentation-based norms?

In answer to these questions, we first illustrated students' argumentation practices and norms in Term 4, and then analysed the scaffolding process from Term 1 onwards. This allowed us to more easily compare the norms students enacted in Term 4 with their emerging but struggling practices in Term 1. In our analysis, we emphasised the emergence and students' later fluency of these norms; the teacher's changing role to diagnose and respond in scaffolding students during the emergence, development and stabilising of norms; and the relationship between argumentationbased inquiry and scaffolding of classroom norms. These three areas are elaborated below.

\subsection{Norms of argumentation-based inquiry}

Importantly, the norms we have discussed come from a classroom practicing argumentation-based inquiry, including norms relevant to both small group and whole class situations. We took inquiry as a process of collaboratively addressing complex, ambiguous tasks that require negotiation and mathematical evidence. The norms of mathematical inquiry follow those proposed by other researchers (e.g., Cobb, 1999; 2002; Franke et al., 2015; McClain \& Cobb, 2001; Yackel \& Cobb, 1996) that go beyond simply explaining one's own work to engage with others' ideas (e.g., active listening, explaining and justifying ideas, building on others ideas, and sharing incomplete ideas). Our focus on argumentation practices in inquiry emphasised the negotiation and classroom discourse aspects. There is intellectual risk in being willing to generate emerging ideas and anticipate critique in these situations, emphasising the relationship between cognitive and long-term social scaffolding that engages student trust (Goos, 2004; Siegel \& Borasi, 1996; Webb et al., 2014; Williams \& Baxter, 1996).

Research has pointed to problems with forms of inquiry, for example those which focus on activity but not depth of content (Artigue \& Blomh øj, 2013) or on content without a sense of purpose and utility of that content (Ainley, Pratt \& Hansen, 2006) or on open-ended inquiry which lacks support and guidance (Kirschner, Sweller \& Clark, 2006). To address these problems, we have included the development of norms within lessons rich in purposeful and useful mathematical content and emphasised the teacher's role in scaffolding these norms. By looking at the development of norms over time, the focus was on both students' and the teacher's actions in-the-moment (Franke et al., 2015). 
This aspect responded to Yackel and Cobb's (1996) challenge to address the taken-as-shared mechanics of normsboth how to respond and when it is appropriate to do so. Studying the development of classroom norms over time and in-the-moment provided insight into how norms of argumentation-based inquiry emerged, developed and stabilised. It further highlighted how teachers play a pivotal role in argumentation-based inquiry due to the inter-related nature of how these norms evolve and the dynamic role of the teacher in scaffolding them.

\subsection{Scaffolding}

Importantly, inquiry-based learning depends on teacher guidance (e.g., Hmelo-Silver, Duncan \& Chinn, 2007), an adaptive practice that teachers find challenging (Webb, 2008). Kaye Bluett's scaffolding strategies were meaningful rather than formulaic in that the focus of her energies was not the strategies themselves, but the norms she chose to develop. In Term 1, for example, instead of simply telling students to engage in active listening, she aimed to persuade students of the utility of this norm by introducing the reasoning behind active listening and creating contexts in which active listening made sense. The problems she gave students initially were non-routine, but shorter and less open-ended so that they could experience success with both creating and sharing multiple forms of evidence through their representations. Three months later in Term 2, students showed greater comfort with many of these initial practices which likely enabled the introduction and development of more advanced inquiry-based norms. The time between the excerpts in Term 1 and Term 4 was approximately nine months, a non-trivial amount of time.

In line with our view on scaffolding as entailing frequent diagnoses, responsive actions and gradual handover to independence (Smit et al., 2013), we focused our analysis on the teacher's diagnoses and intentions at different stages of the year as students progressed. To support this analysis, we looked for relationships of how she intended to respond to what she had observed as expressed in interviews, and her responsive strategies in lessons. The teacher's strategies included the use of posters as scaffolds with expectations, frequent reminders of the norms, positive feedback, using student actions as exemplars, providing and modelling expectations with prompts, and providing many opportunities to enact practices. The teacher kept emphasising that there is more than one way to solve a problem, everyone is expected to think, all ideas are valued and ideas can be questioned or challenged respectfully.

The analysis suggests that the meaningful and longterm scaffolding process helped to foster the practices the teacher chose to develop in that year: active listening, justifying and explaining to peers, sharing incomplete ideas (intellectual risk-taking), and building on others' ideas. Doing so, she helped foster classroom practices in which students went beyond explaining, evidenced in anticipating critique and valuing feedback. Building on Smit and her colleagues (2003), this case study further indicates how scaffolding as a long-term process could be characterized as distributed over lessons and events outside lessons (e.g., diagnosis of student work; expressing intentions in interviews with a researcher); layered (involving both live interaction and strategy development outside of class); and cumulative - the process of handing over to independent use of norms was a cumulative development, fed by many instances of teacher encouragement, positive feedback, and many other responsive teaching strategies. Handover to independence was seen when students fluently enacted the norms when the teacher was not around.

\subsection{Conclusion}

How a teacher can scaffold students' development of inquiry-based norms in a primary classroom over the year is fairly unchartered territory (Ing et al., 2015). We would argue that a key reason for the lack of uptake of inquiry in mathematics is the dearth of knowledge about how teachers develop and progress, from scratch, inquiry-based norms in their classroom in the process of teaching. This study contributes to a greater understanding of how norms of argumentation-based inquiry evolve over a year and a teacher's strategies in scaffolding those norms as they emerged, developed and stabilised. In each stage, we emphasised how she diagnosed and responded to students' evolving norms with an aim to move them towards independence. Understanding this changing process is important for the field because inquiry-based pedagogies are not yet common practice in mathematics classrooms despite decades of research. An implication of this study, therefore, is to provide an initial template of what to expect in terms of students' adoption of argumentation-based inquiry norms at different stages of experience over a year and how a primary teacher can scaffold these norms.

Although the mathematical content that students learned was not the focus of this article, research has promoted the alignment between social norms and development of students' mathematical learning (e.g., Hmelo-Silver \& Barrows, 2008; Ing et al., 2015; Webb et al., 2014). This gives us some confidence that the children benefited from the teacher's scaffolding of argumentation-based inquiry norms not just socially, but also mathematically. As a case study, our analysis is considered a proof of principle: It is possible to achieve this, and the results illustrate what we assume to be key ingredients of the teacher's approach. However, case studies-though potentially offering theoretical 
generalisability—have limited statistical generalisability. Working on larger scale establishment of such argumentation norms would therefore be a productive topic for future research.

Acknowledgments This research was funded by the Australian Research Council (DP120100690). The authors wish to thank Sue for her insights in teaching and Janine for her timely support during analysis of the data.

Open Access This article is distributed under the terms of the Creative Commons Attribution 4.0 International License (http://creativecommons.org/licenses/by/4.0/), which permits unrestricted use, distribution, and reproduction in any medium, provided you give appropriate credit to the original author(s) and the source, provide a link to the Creative Commons license, and indicate if changes were made.

\section{References}

Ainley, J., Pratt, D., \& Hansen, A. (2006). Connecting engagement and focus in pedagogic task design. British Educational Research Journal, 32(1), 23-38.

Artigue, M., \& Blomhøj, M. (2013). Conceptualizing inquiry-based education in mathematics. ZDM - The International Journal on Mathematics Education, 45(6), 797-810.

Brown, J. S., Collins, A., \& Duguid, P. (1989). Situated cognition and the culture of learning. Educational Researcher, 18(1), 32-42.

Cazden, C. B. (2001). Classroom discourse (2nd ed.). Portsmouth, NH: Heinemann.

Cobb, P. (1999). Individual and collective mathematical development: The case of statistical data analysis. Mathematical Thinking and Learning, 1(1), 5-43.

Cobb, P. (2002). Reasoning with tools and inscriptions. Journal of the Learning Sciences, 11(2-3), 187-215.

Cobb, P., Confrey, J., diSessa, A., Lehrer, R., \& Schauble, L. (2003). Design experiments in educational research. Educational Researcher, 32(1), 9-13.

Enyedy, N., \& Stevens, R. (2015). Analyzing collaboration. In K. Sawyer (Ed.), Cambridge Handbook of the Learning Sciences (pp. 191-212) (2nd ed.). New York: Cambridge University Press.

Fielding-Wells, J. (2010). Linking problems, conclusions and evidence: Primary students' early experiences of planning statistical investigations. In C. Reading (Ed.), Proceedings of the 8th International Conference on Teaching Statistics, Ljubljana, Slovenia. Voorburg, the Netherlands: International Statistical Institute.

Franke, M. L., Turrou, A. C., Webb, N. M., Ing, M., Wong, J., Shin, N., \& Fernandez, C. (2015). Student engagement with others' mathematical ideas. The Elementary School Journal. doi:10.1086/683174 (in press).

Fry, K. (2013). Students 'holding' the moment: learning mathematics in an inquiry mathematics classroom. Proceedings of the 36th Annual Conference of the Mathematics Education Research Group of Australasia (Vol. 1, pp. 306-313). Sydney: MERGA.

Goos, M. (2004). Learning mathematics in a classroom community of inquiry. Journal for Research in Mathematics Education, 35(4), 258-291.

Herrenkohl, L. R., Palincsar, A. S., DeWater, L. S., \& Kawasaki, K. (1999). Developing scientific communities in classrooms: A sociocognitive approach. Journal of the Learning Sciences, 8(34), 451-493.
Hmelo-Silver, C. E., Barrows, H. S. (2008). Facilitating collaborative knowledge building. Cognition andinstruction, 26(1), 48-94.

Hmelo-Silver, C. E., Duncan, R. G., \& Chinn, C. A. (2007). Scaffolding and achievement in problem-based and inquiry learning: A response to Kirschner, Sweller, and Clark (2006). Educational Psychologist, 42(2), 99-107.

Ing, M., Webb, N. M., Franke, M. L., Turrou, A. C., Wong, J., Shin, N., \& Fernandez, C. (2015). Student participation in elementary mathematics classrooms: the missing link between teacher practices and student achievement? Educational Studies in Mathematics, 1-16 (in press).

Kirschner, P. A., Sweller, J., \& Clark, R. E. (2006). Why minimal guidance during instruction does not work: An analysis of the failure of constructivist, discovery, problem-based, experiential, and inquiry-based teaching. Educational Psychologist, 41(2), $75-86$.

Linn, M. C. (2000). Designing the knowledge integration environment. International Journal of Science Education, 22(8), 781-796.

McClain, K., \& Cobb, P. (2001). An analysis of development of sociomathematical norms in one first-grade classroom. Journal for Research in Mathematics Education, 32(3), 236-266.

McCrone, S. S. (2005). The development of mathematical discussions: An investigation in a fifth-grade classroom. Mathematical Thinking and Learning, 7(2), 111-133.

Mercer, N. (2008). The seeds of time: Why classroom dialogue needs a temporal analysis. Journal of the Learning Sciences, 17(1), $33-59$.

Powell, A. B., Francisco, J. M., \& Maher, C. A. (2003). An analytical model for studying the development of learners' mathematical ideas and reasoning using videotape data. The Journal of Mathematical Behavior, 22(4), 405-435.

Quintana, C., Reiser, B. J., Davis, E. A., Krajcik, J., Fretz, E., Duncan, R. G., et al. (2004). A scaffolding design framework for software to support science inquiry. Journal of the Learning Sciences, 13(3), 337-386.

Reitman, W. R. (1965). Cognition and thought: An information processing approach. Oxford UK: Wiley.

Renshaw, P. D. (2013). The social cultural and emotional dimensions of scaffolding. Learning, Culture and Social Interaction, 2(1), $56-60$.

Schukajlow, S., Kolter, J., \& Blum, W., (2015). Scaffolding mathematical modelling with a solution plan. ZDM Mathematics Education, 47(7). doi:10.1007/s11858-015-0707-2 (this issue).

Sherin, B., Reiser, B. J., \& Edelson, D. (2004). Scaffolding analysis: Extending the scaffolding metaphor to learning artifacts. Journal of the Learning Sciences, 13(3), 387-421. doi:10.1207/ s15327809jls1303_5.

Siegel, M., \& Borasi, R. (1994). Demystifying mathematics education through inquiry. In P. Ernest (Ed.), Constructing mathematical knowledge: Epistemology and mathematical education (pp. 201-215). Abingdon: Routledge.

Siegel, M., \& Borasi, R. (1996). Demystifying mathematics education through inquiry. In P. Ernest (Ed.), Constructing mathematical knowledge (pp. 201-215). London: Falmer Press.

Smit, J., \& van Eerde, D. (2013). What counts as evidence for the long-term realisation of whole-class scaffolding? Learning, Culture and Social Interaction, 2(1), 22-31.

Smit, J., van Eerde, H. A. A., \& Bakker, A. (2013). A conceptualisation of whole-class scaffolding. British Educational Research Journal, 39(5), 817-834.

Speer, N. M., \& Wagner, J. F. (2009). Knowledge needed by a teacher to provide analytic scaffolding during undergraduate mathematics classroom discussions. Journal for Research in Mathematics Education, 40(5), 530-562. 
Tabak, I. (2004). Synergy: A complement to emerging patterns of distributed scaffolding. Journal of the Learning Sciences, 13(3), 305-335.

Towers, J., Martin, L. C., \& Heater, B. (2013). Teaching and learning mathematics in the collective. The Journal of Mathematical Behavior, 32(3), 424-433.

van de Pol, J., Volman, M., \& Beishuizen, J. (2010). Scaffolding in teacher-student interaction: A decade of research. Educational Psychology Review, 22(3), 271-296.

van de Pol, J., Volman, M., \& Beishuizen, J. (2011). Patterns of contingent teaching in teacher-student interaction. Learning and Instruction, 21(1), 46-57.

Webb, N. M. (2008). Teacher practices and small-group dynamics in cooperative learning classrooms. In R. Gillies, A. Ashman, \& J. Terwel (Eds.), The teacher's role in implementing cooperative learning in the classroom (pp. 201-221). New York: Springer.

Webb, N. M., Franke, M. L., Ing, M., Wong, J., Fernandez, C. H., Shin, N., \& Turrou, A. C. (2014). Engaging with others' mathematical ideas: Interrelationships among student participation, teachers' instructional practices, and learning. International Journal of Educational Research, 63, 79-93.

Wells, J. (2014). Developing argumentation in mathematics: The role of evidence and context. Unpublished doctoral dissertation, The University of Queensland.

Williams, S. R., \& Baxter, J. A. (1996). Dilemmas of discourse-oriented teaching in one middle school mathematics classroom. The Elementary School Journal, 97(1), 21-38.

Yackel, E., \& Cobb, P. (1996). Sociomathematical norms, argumentation, and autonomy in mathematics. Journal for Research in Mathematics Education, 27(4), 458-477.

Zack, V., \& Reid, D. A. (2003). Good-enough understanding: Theorising about the learning of complex ideas (part 1). For the Learning of Mathematics, 23(3), 43-50. 